\title{
Diabetiker werden ist nicht schwer!
}

\begin{abstract}
_ Die Zahlen sind alarmierend. Wenn es so weitergeht und die Auguren Recht haben, sind wir bald alle Diabetiker, so das Fazit des diesjährigen Diabeteskongresses. Wollte man das verhindern, müsste man die Blutzuckernormwerte anheben. Das will aber keiner so richtig, weder die Ärzte noch die Pharmaindustrie. Nun haben die Krankenkassen einen interessanten Vorschlag gemacht: Man möge doch bitte den Patienten selbst entscheiden lassen, ob er Diabetiker sein möchte oder nicht. Das nennt man dann "shared decision making“.

Diabetes ist sicherlich eine schlimme Erkrankung. Besonders schlimm ist, dass er nicht weh tut, sonst wären die Behandlungsergebnisse auch besser. Noch schlimmer kann es werden, wenn der Diabetiker an einen Arzt gerät, der zu
\end{abstract}

ehrgeizig ist und den $\mathrm{HbA}_{1 c}$-Wert zu weit nach unten drückt, egal wie. Das kann für den Betroffenen tödlich enden: Intervention zwar gelungen, aber Patient leider verstorben. Frei nach Wilhelm Busch: Diabetiker werden ist nicht schwer, Diabetiker sein dagegen sehr.

Ein ewiges Streitthema ist die richtige Diabetes-Diät (s. auch Meldung rechts). Die einen sagen, nur Kohlenhydrate, um die Bauchspeicheldrüse zu trainieren, die anderen plädieren für nur Fett, schließlich müsse die Bauchspeicheldrüse geschont werden. Der offizielle Kompromiss in Sachen Diät lautet deshalb: 25\% Kohlenhydrate, 25\% Fett und 25\% Proteine. Und was ist mit den restlichen $25 \%$ ? Nix da, der Patient soll ja abnehmen.

Dr. Peter Stiefelhagen

\section{Infektionsquelle}

\section{Riskanter Rohmilch-Genuss}

\section{Krankheitsausbrüche in Zusammen- hang mit dem Konsum von Kuhmilch (-produkten) sind fast immer durch Rohmilch bedingt, wie eine Analyse der Centers of Disease Control zeigt.}

— Die Analyse basiert auf den Daten aller Krankheitsausbrüche in den USA in den Jahren 2009 bis 2014, die durch Verunreinigung von Kuhmilch oder -käse mit EHEC, Salmonella spp., Listeria monocytogenes oder Campylobacter spp. ausgelöst worden waren. Im Schnitt gab es im Rahmen solcher Ausbrüche pro Jahr 761 Erkrankungen und 22 Klinikeinweisungen. Obwohl Rohmilch bzw. Rohmilchkäse nur bei etwa 3,2\% bzw. 1,6\% der Bevölkerung auf dem Speiseplan stehen, waren sie ursächlich für 96\% der Erkrankungen.

Das Risiko für eine Erkrankung durch eines der vier Pathogene ist demnach bei Rohmilchkonsumenten 840 mal so hoch wie bei Konsumenten von erhitzter Milch, das Risiko für Krankenhausaufnahmen ist um den Faktor 45 erhöht.

- bs

- Costard Set al. Emerging Infectious Diseases 2017; online first Mai 2017
Nudeln besser Mittags essen!

\section{Metabolismus und zirkadianer Rhythmus}

\section{Abends keine Kohlenhydrate?}

\section{Patienten mit gestörtem Glukosestoff- wechsel sollten ein kohlenhydrat- reiches Dinner vermeiden, so das Er- gebnis einer klinischen Studie.}

_ 14 Probanden erhielten eine Diät, bei der morgens $65 \%$ der Kalorien in Form von Kohlenhydraten, 20\% als Fett und $15 \%$ als Protein gegeben wurden. Nach 16.30 Uhr erhielten sie 35\% Kohlenhydrate, 50\% Fett und 15\% Eiweiß. Bei einer zweiten Gruppe mit 15 Probanden bestand die Diät aus 35\% Kohlenhydrate, $50 \%$ Fett und 15\% Protein morgens, abends 65\% Kohlenhydrate, 20\% Fett und 15\% Protein. Nach 4 Wochen bekamen alle Teilnehmer eine Testmahlzeit. Dabei wurden metabolische Parameter wie Nüchtern- und postprandialer Blutzucker, Fettsäuren und die Spiegel von Insulin und Inkretinen bestimmt.

„Die Ergebnisse sprechen dafür, dass eine fettreiche Ernährung am Morgen mit einer kohlenhydratreichen Diät am Abend einen ungünstigen Effekt auf die glykämische Kontrolle entfaltet", so Dr. Olga Pivovarova, Potsdam. Dies gelte allerdings nicht für Stoffwechselgesunde. Mit anderen Worten: Bei Prädiabetikern sinkt die Glukosetoleranz in der zweiten Tageshälfte stärker als bei Gesunden. - sti

- Deutscher Diabetes Kongress 2017, 25.5.2017 in Hamburg 